\title{
Article \\ Optimization of Exopolysaccharide (EPS) Production by Rhodotorula mucilaginosa sp. GUMS16
}

\author{
Oseweuba Valentine Okoro ${ }^{1, *(\mathbb{D})}$, Amir Reza Gholipour ${ }^{2}$, Faezeh Sedighi ${ }^{2}$, Amin Shavandi ${ }^{1, *(D)}$ \\ and Masoud Hamidi 1,2,*(D) \\ 1 BioMatter-Biomass Transformation Lab (BTL), École Polytechnique de Bruxelles, Université Libre \\ de Bruxelles, Avenue F.D. Roosevelt, 50-CP 165/61, 1050 Brussels, Belgium \\ 2 Department of Medical Biotechnology, Faculty of Paramedicine, Guilan University of Medical Sciences, \\ Rasht 4477166595, Iran; gholipoor.amirreza7@gmail.com (A.R.G.); faezeh.sedighi20@gmail.com (F.S.) \\ * Correspondence: oseweuba.okoro@ulb.be (O.V.O.); amin.shavandi@ulb.be (A.S.); \\ masoud.hamidi@ulb.be (M.H.)
}

Citation: Okoro, O.V.; Gholipour, A.R.; Sedighi, F.; Shavandi, A.;

Hamidi, M. Optimization of

Exopolysaccharide (EPS) Production by Rhodotorula mucilaginosa sp. GUMS16. ChemEngineering 2021, 5, 39. https://doi.org/10.3390/ chemengineering5030039

Academic Editor: Andrew S. Paluch

Received: 11 June 2021

Accepted: 20 July 2021

Published: 21 July 2021

Publisher's Note: MDPI stays neutral with regard to jurisdictional claims in published maps and institutional affiliations.

Copyright: (c) 2021 by the authors. Licensee MDPI, Basel, Switzerland. This article is an open access article distributed under the terms and conditions of the Creative Commons Attribution (CC BY) license (https:// creativecommons.org/licenses/by/ $4.0 /)$.

\begin{abstract}
Exopolysaccharides (EPSs) are important biopolymers with diverse applications such as gelling compounds in food and cosmetic industries and as bio-flocculants in pollution remediation and bioplastics production. This research focuses on enhancing crude EPS production from Rhodotorula mucilaginosa sp. GUMS16 using the central composite design method in which five levels of process variables of sucrose, $\mathrm{pH}$, and ammonium sulfate were investigated with sucrose and ammonium sulfate serving as carbon and nitrogen sources during microbial incubation. The optimal crude EPS production of $13.48 \mathrm{~g} / 100 \mathrm{~mL}$ was achieved at $1 \mathrm{~g} / 100 \mathrm{~mL}$ of sucrose concentration, $14.73 \mathrm{~g} / 100 \mathrm{~mL}$ of ammonium sulfate at $\mathrm{pH}$. Variations in ammonium sulfate concentrations $(1.27-14.73 \mathrm{~g} / 100 \mathrm{~mL})$ presented the most significant effects on the crude EPS yield, while changes in sucrose concentrations $(1-5 \mathrm{~g} / 100 \mathrm{~mL})$ constituted the least important process variable influencing the EPS yield. The Rhodotorula mucilaginosa sp. GUMS16 may have the potential for large-scale production of EPS for food and biomedical applications.
\end{abstract}

Keywords: exopolysaccharide; Rhodotorula mucilaginosa; central composite method; experimental optimization

\section{Introduction}

The use of polysaccharides, in the production of hydrogels, films, aerogels etc. for application in tissue engineering, is well known [1-6]. The current study, therefore, proposes the biosynthesis of valuable exopolysaccharides (EPSs), from carbon and nitrogen substrates, under the action of microbes by enabling the chemical condensation of intracellular nucleotide sugars and starter precursors in several metabolic pathways [7,8]. The biosynthesis of high molecular weight EPS incorporates the biosorption of nutrients [7,8]. The produced EPSs are water-soluble long-chain branched sugar derivatives that may exist as homopolymers or heteropolymers and are characterized by a wide diversity of chemical structures $[9,10]$. These branched sugar derivatives may also contain non-polysaccharide substituents such as phosphate, acetyl, and glycerol $[10,11]$. Compared to conventional plant or algal sourced polysaccharides, EPSs are characterized by lower production costs and more efficient downstream processing, illustrated by the potential for continuous harvesting from the cell-free culture supernatant [12]. EPSs are also characterized by unique amphiphilic, gelling, biocompatibility, biodegradability, bioactivity properties have diverse biomedical, environmental and food applications $[2,7,13,14]$. These properties highlight that EPS may be particularly useful in tissues engineering $[15,16]$. Despite the benefits, the commercial viability of EPS production has thus far been limited due to the low yields of typically $<9 \mathrm{~g} / 100 \mathrm{~mL}[3,17]$. It is, therefore, necessary to explore opportunities for 
enhanced EPS production via proper microbial strain selection and EPS production optimization. In line with the need for appropriate microbial strain selection, a previous study identified that the new cold-adapted yeast of Rhodotorula mucilaginosa sp. GUMS16 has biomedical application for skin wound healing [18]. The quantitative variation of fungal EPS yields is largely dependent on the processing conditions of culture medium composition and fermentation conditions [19]. Therefore, the present study investigates the preferred culture medium composition (i.e., carbon and nitrogen content) and fermentation conditions (i.e., $\mathrm{pH}$ ) for enhanced EPS production from the Rhodotorula mucilaginosa sp. GUMS16 [20] using sucrose and ammonium sulfate as carbon and nitrogen precursors. Additionally, given the important role of $\mathrm{pH}$ in regulating microbial functions [21,22], the effect of $\mathrm{pH}$ value on EPS yield was also investigated. Previous studies reported optimizing EPS production from different bacteria such as Micrococcus roseus and Lactobacillus plantarum, respectively [23,24]. For instance, Ermiş et al. [25], optimized the EPS yield from Lactobacillus brevis and showed that the optimal EPS yield of $3.5 \mathrm{~g} / 100 \mathrm{~mL}$ was obtained when the initial process $\mathrm{pH}$ of the medium was 6.5 with $18 \mathrm{~h}$ incubation time at $35^{\circ} \mathrm{C}$. The novelty of the present study is to focus on the optimization of the yield of EPS from the cold-adapted yeast of Rhodotorula mucilaginosa sp. GUMS16. The central composite design (CCD) method was employed to optimize EPS yield and the significance of the process parameters on EPS yield are also assessed in this study.

\section{Materials and Methods}

\subsection{Microorganism}

The Rhodotorula mucilaginosa sp. GUMS16, a cold-adapted yeast we previously reported in [26] was employed. Briefly, Rhodotorula mucilaginosa sp. GUMS16 was isolated from leaf debris of Deylaman jungle, Guilan, Iran and then initially cultured using standard potato dextrose agar (PDA) plates (HiMedia, New Delhi) containing the culture medium. The incubation was undertaken at the temperature of $25^{\circ} \mathrm{C}$ for $24 \mathrm{~h}$. The resulting Rhodotorula mucilaginosa sp. GUMS16 was manifested as orange-colored colonies.

\subsection{Preparation of Inoculum}

The $24 \mathrm{~h}$-old culture, at the logarithmic stage of growth, with an optical density $(600 \mathrm{~nm})$ of 0.8 , was used as the inoculum in all experiments. These cultures were used as inoculum at $10 \%(v / v)$ for all the experiments.

\subsection{Experimental Design, Statistical Analysis, and Optimization}

CCD methodology based on using a five-level rotatable central composite design was employed to optimize the culture conditions of $\mathrm{pH}$, sucrose, and ammonium sulfate concentrations for enhanced EPS production by Rhodotorula mucilaginosa sp. GUMS16. A total of 20 experiments were conducted. Based on the ranges of the process variables specified above, the coded values were determined as follows [27];

$$
X_{i}=\frac{X_{i}-X_{0}}{\Delta X}
$$

where $X_{i}$ denotes the coded value of the process variable; $X_{i}$ is the process variable's actual value; $X_{0}$ denotes the actual value of $X_{i}$ at the center point with the step change value denoted as $\Delta X$. Table 1.

The values of the process variables and their associated coded values are presented in 
Table 1. Coded and actual levels used in the CCD experimental method.

\begin{tabular}{cccccc}
\hline Parameters & & \multicolumn{3}{c}{$\begin{array}{c}\text { Coded and Actual Values for the } \\
\text { Levels in the Experimental Design }\end{array}$} \\
\hline Levels & Low axial & Low & Center & High & High axial \\
\hline $\mathrm{pH}$ value, $p$ (dimensionless) & -2 & -1 & 0 & +1 & +2 \\
\hline Sucrose concentration, $S(\mathrm{~g} / 100 \mathrm{~mL})$ & 0.64 & 2 & 4 & 6 & 5 \\
\hline Ammonium sulfate concentration, $A(\mathrm{~g} / 100 \mathrm{~mL})$ & 1.27 & 4 & 8 & 12 & 14.73 \\
\hline
\end{tabular}

The significance of each process variable on the EPS yield was assessed based on the analysis of the associated student $F$-value of the process variable compared to the critical $F$-value (determined to be 3.37 for a $95 \%$ confidence level) of the experimental data as described in the literature [28,29]. In this approach, the significance of a process variable is determined by the magnitude by which the statistical student $F$-value exceeds the critical $F$-value. The significance of the variables was also assessed using the $p$-value of each process variable such that the level of significance was determined by the magnitude of difference of $p$-value from 0.05 for a $95 \%$ confidence level. The experimental results of the central composite design were then employed to generate an empirical relation in accordance with the second-order polynomial equation as follows:

$$
Y_{E P S}=X_{0}+\sum_{i=1}^{3} b_{i} X_{i}+\sum_{i=1}^{3} b_{i i} X_{i}^{2}+\sum_{i=1}^{3} \sum_{j=1} b_{i j} X_{i} X_{j}
$$

where $Y_{E P S}$ denotes the EPS yield, $\mathrm{g} / 100 \mathrm{~mL}, X_{0}$ represents the model intercept, $X_{i}\left(X_{j}\right)$ represents the $i$ th $(j$ th) system variable $(\mathrm{pH}$, sucrose, and ammonium sulfate concentrations, $\mathrm{g} / 100 \mathrm{~mL}), b_{i}, b_{i i}$, and $b_{i j}$ represent the model regression coefficients.

The sufficiency of the developed empirical model was initially assessed via the determination of the associated correlation coefficient $\left(R^{2}\right)$ [30]. Further assessments involved statistical analysis using analysis of variance (ANOVA). Statistical analysis of the data was performed using the statistical software of Minitab ${ }^{\circledR}$ 17.1.0 (Minitab, Inc., State College, PA, USA). The empirical model was subsequently employed to determine the values of the process variables that will facilitate an optimal EPS yield via the numerical optimization algorithm method available in Minitab software. The estimated operating conditions for the optimal EPS yield were then validated experimentally. The predicted optimal EPS yield and the experimentally optimal EPS yield were subsequently compared.

\subsection{Culture Conditions}

The Potato Dextrose Broth (PDB) (HiMedia, New Delhi) containing 2.4 g/100 mL of dextrose was modified with different combinations of the independent variables $(\mathrm{pH}$, sucrose, and ammonium sulfate concentrations), following the experimental design. The ranges of the $\mathrm{pH}$ value, sucrose, and ammonium sulfate concentrations investigated were specified as $2-6,1-5(\mathrm{~g} / 100 \mathrm{~mL})$ and $4-12(\mathrm{~g} / 100 \mathrm{~mL})$, respectively. All experiments were conducted in $250 \mathrm{~mL}$ Erlenmeyer flasks containing $90 \mathrm{~mL}$ of the growth medium. After inoculation, the flasks were incubated with shaking at $150 \mathrm{rpm}$ in the dark for 5 days at $25^{\circ} \mathrm{C}$. The sucrose was added in addition to the dextrose which present in PDB, since sucrose has reported as the preferred carbon source for EPS production [31,32]. Furthermore, most microorganisms have been reported to use ammonium salts or amino acids as nitrogen sources for polysaccharide production [33], and several studies had previously demonstrated the sufficiency of the use of ammonium sulfate to achieve optimal EPS yields $[23,34]$. Therefore, ammonium sulfate was selected as the preferred nitrogen source. 


\subsection{Recovery of the EPS}

After incubation, the EPS containing media was centrifuged at $8500 \times g$ for $30 \mathrm{~min}$ at $4{ }^{\circ} \mathrm{C}$ and the supernatant containing the EPS was kept. The EPS was precipitated from the supernatant using the drop-by-drop addition of cold $96 \mathrm{wt} . \%$ ethanol with simultaneous stirring followed by overnight incubation at $4{ }^{\circ} \mathrm{C}$. The precipitated EPS was also washed with cold ethanol followed by $8500 \times g$ centrifugation for 20 min at $4{ }^{\circ} \mathrm{C}$. After evaporation of ethanol (i.e., when the mass of the EPS pellets remained constant), the resulting EPS pellet was dissolved in distilled water, frozen and lyophilized using a freeze dryer instrument (Christ Alpha 1-2 LDplus, Nemacka, Germany). Finally, the mass of EPS produced was measured using a precision analytical balance (Sartorius Quintix ${ }^{\circledR}$, Göttingen, Germany), in g. The yield was reported as the mass of EPS in g per $100 \mathrm{~mL}$ of the substrate and denoted as $Y_{E P S}$. Figure 1 shows the schematic diagram of the EPS extraction and recovery process.

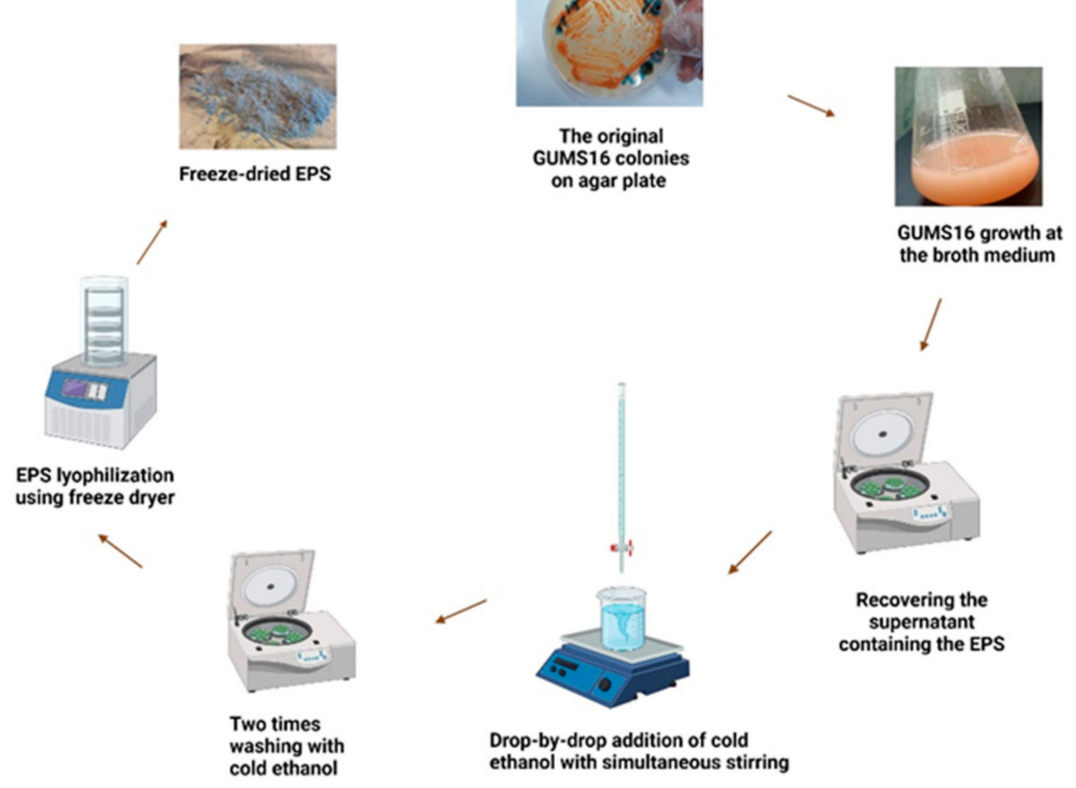

Figure 1. Exopolysaccharide extraction and recovery process from Rhodotorula mucilaginosa sp. GUMS16.

\section{Results and Discussions}

\subsection{Model Fitting}

The CCD and the yields for the different levels of the process variables investigated are shown in Table 2. Table 2 shows that the highest EPS yield is $13.05 \mathrm{~g} / 100 \mathrm{~mL}$ at $\mathrm{pH}$, sucrose concentration and ammonium sulfate concentration conditions of $4,3 \mathrm{~g} / 100 \mathrm{~mL}$ and $14.73 \mathrm{~g} / 100 \mathrm{~mL}$, respectively. Table 2 highlights the favorable impact of the nitrogen source in EPS yield when Rhodotorula mucilaginosa sp. GUMS16 was employed. Therefore, EPS yield positively correlates with a higher nitrogen source concentration, highlighting the important role of nitrogen in the biosynthesis of proteins and polysaccharides by the yeast $[35,36]$.

Employing the experimental results presented in Table 2 in conjunction with the model form highlighted in Equation (3), to generate a fitted empirical relation describing EPS yield as a function of the process variables as follows.

$$
\begin{gathered}
Y_{E P S}=-4.82+1.641 p-0.447 S+1.310 A-0.1726 p^{2}+0.0821 S^{2} \\
-0.0138 A^{2}+0.0266 p \times S+0.0039 p \times A-0.0414 s \times A
\end{gathered}
$$


Table 2. The yield of crude exopolysaccharides (EPSs) generated at the different process conditions.

\begin{tabular}{|c|c|c|c|c|c|c|c|}
\hline \multirow[t]{2}{*}{ Runs } & \multicolumn{3}{|c|}{ Coded Values of Parameters } & \multicolumn{3}{|c|}{ Actual Values of Parameters } & \multirow{2}{*}{$\begin{array}{c}\text { Response } \\
Y_{E P S} \\
(\mathrm{~g} / 100 \mathrm{~mL})\end{array}$} \\
\hline & $p$ & $\begin{array}{c}S \\
(\mathrm{~g} / 100 \mathrm{~mL})\end{array}$ & $\begin{array}{c}A \\
(\mathrm{~g} / 100 \mathrm{~mL})\end{array}$ & $p$ & $\begin{array}{c}S \\
(\mathrm{~g} / 100 \mathrm{~mL})\end{array}$ & $\begin{array}{c}A \\
(\mathrm{~g} / 100 \mathrm{~mL})\end{array}$ & \\
\hline 1 & -1.68 & 0 & 0 & 0.64 & 3 & 8 & 2.59 \\
\hline 2 & 0 & 0 & 0 & 4 & 3 & 8 & 8.13 \\
\hline 3 & -1 & 1 & 1 & 2 & 5 & 12 & 10.09 \\
\hline 4 & 0 & 0 & -1.68 & 4 & 3 & 1.27 & 0.19 \\
\hline 5 & -1 & -1 & 1 & 2 & 1 & 12 & 11.54 \\
\hline 6 & 0 & 0 & 0 & 4 & 3 & 8 & 7.23 \\
\hline 7 & 1 & 1 & 1 & 6 & 5 & 12 & 10.64 \\
\hline 8 & 0 & 0 & 0 & 4 & 3 & 8 & 7.00 \\
\hline 9 & -1 & 1 & -1 & 2 & 5 & 4 & 2.83 \\
\hline 10 & -1 & -1 & -1 & 2 & 1 & 4 & 2.93 \\
\hline 11 & 0 & 0 & 0 & 4 & 3 & 8 & 7.53 \\
\hline 12 & 0 & 0 & 0 & 4 & 3 & 8 & 6.84 \\
\hline 13 & 0 & 1.68 & 0 & 4 & 6.36 & 8 & 7.38 \\
\hline 14 & 1 & -1 & -1 & 6 & 1 & 4 & 2.93 \\
\hline 16 & 1.68 & 0 & 0 & 7.36 & 3 & 8 & 7.99 \\
\hline 17 & 1 & 1 & -1 & 6 & 5 & 4 & 3.23 \\
\hline 18 & 1 & -1 & 1 & 6 & 1 & 12 & 11.64 \\
\hline 19 & 0 & 0 & 0 & 4 & 3 & 8 & 7.91 \\
\hline 20 & 0 & 0 & 1.68 & 4 & 3 & 14.73 & 13.05 \\
\hline
\end{tabular}

$p$ denotes $\mathrm{pH}$ value, $S$ denotes sucrose concentration, $A$ denotes ammonium sulfate concentration and $Y_{E P S}$ denotes crude EPS yield.

This fitted relation was determined to have a coefficient of determination $\left(R^{2}\right)$ value of 0.9615 , indicating that the fitted relation did not sufficiently describe only $3.85 \%$ of the experimental dates data and that the model is sufficient to describe the experimental results given the $\mathrm{R}^{2}$ value exceeds the lowest acceptable $\mathrm{R}^{2}$ value of 0.7 for scientific studies $[37,38]$. The fitted relation in Equation (3) was therefore employed in assessing the effects of the process variables using surface plots in the subsequent section.

\subsection{Effects of the Process Variables}

\subsubsection{Effect of $\mathrm{pH}$}

Figure 2a shows that EPS yield initially increased from $5 \mathrm{~g} / 100 \mathrm{~mL}$ to $8 \mathrm{~g} / 100 \mathrm{~mL}$ as the $\mathrm{pH}$ increases from 0.64 to 4 , with the EPS yield decreasing with further increments in the $\mathrm{pH}$ value. This observation is indicative of the unfavorable impact of alkaline environments on EPS yield. It is consistent with the literature since the EPS chemical structure is modified and disrupted at high $\mathrm{pH}$ conditions [39]. The preference for lower $\mathrm{pH}$ values to enable EPS production is also consistent with earlier studies that showed enhanced EPS production by microbes of Cryptococcus genus, Lactobacillus casei CRL 87 and Lactobacillus confusus TISTR 1498 at $\mathrm{pH}$ values of 4, 6, and 5.5, respectively [31,40]. Notably, while low $\mathrm{pH}$ values may favor EPS production [41], the result suggests that highly acidic conditions (i.e., $\mathrm{pH}<4$ ) may lead to unwanted excessive acidification during EPS accumulation, which may negatively impact the yeast growth. 


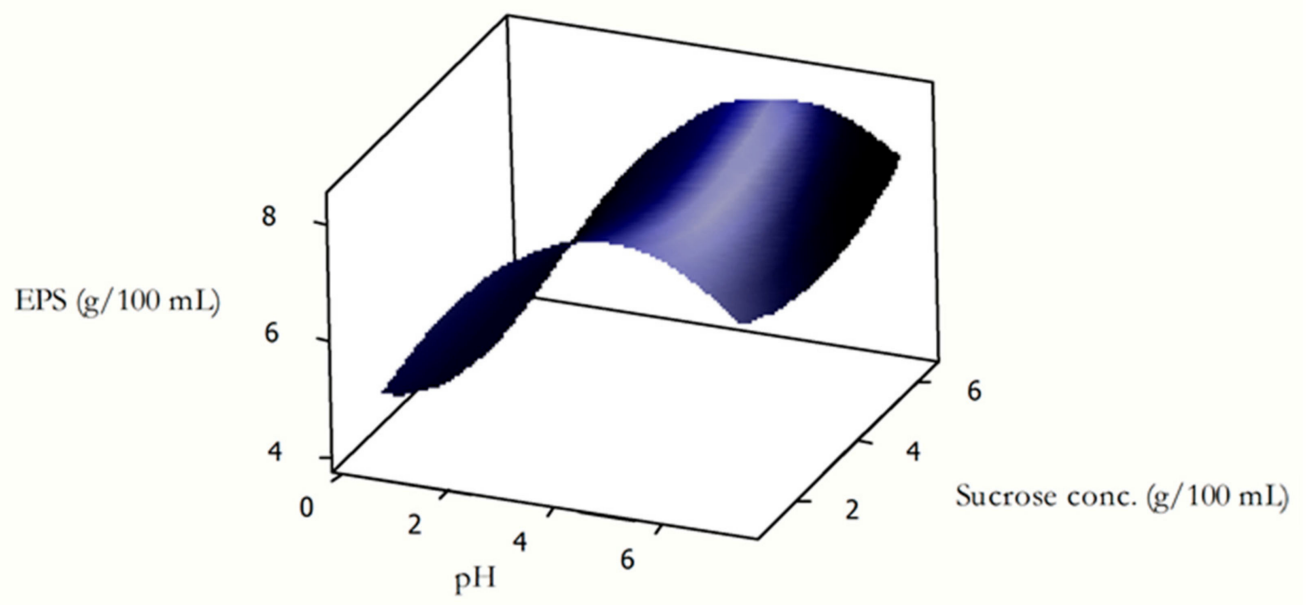

(a)

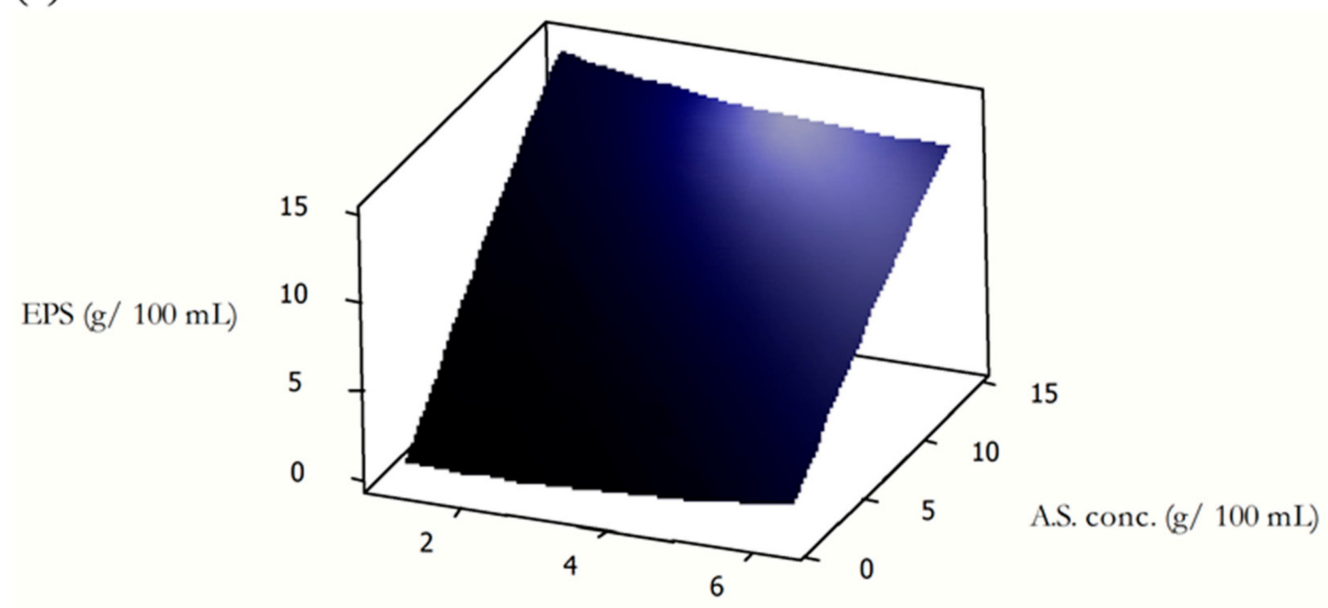

(b)

Sucrose concentration $(\mathrm{g} / 100 \mathrm{~mL})$

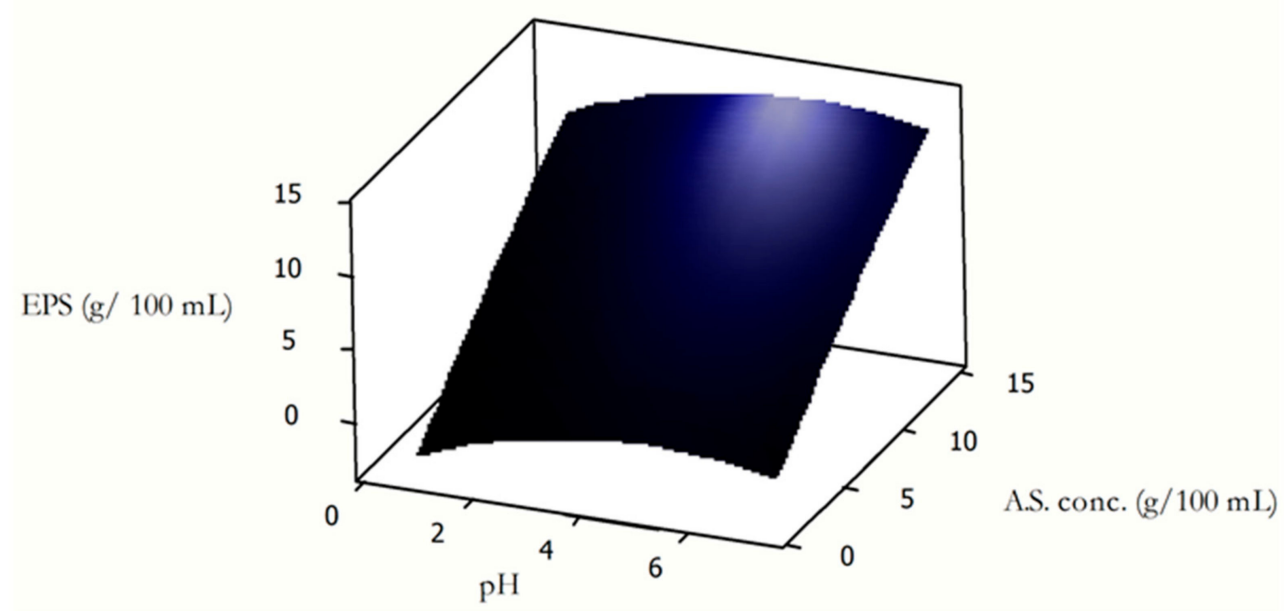

(c)

Figure 2. Surface plot highlighting the effect of process variables on the crude EPS yield (EPS, g/100 mL). (a) denotes the 3D surface plot showing variations in crude EPS yield as $\mathrm{pH}$ and sucrose concentration changes at constant ammonium sulfate concentration of $8 \mathrm{~g} / 100 \mathrm{~mL}$. (b) denotes the 3D surface plot showing variations in crude EPS yield as sucrose concentration and ammonium sulfate concentration changes at a constant $\mathrm{pH}$ of 4 . (c) denotes the 3D surface plot showing variations in crude EPS yield as $\mathrm{pH}$ and ammonium sulfate concentration changes at a constant sucrose concentration of $3 \mathrm{~g} / 100 \mathrm{~mL}$. 


\subsubsection{Effect of Ammonium Sulfate Concentration}

Figure $2 \mathrm{~b}$ highlights a positive correlation between the ammonium sulfate concentration (i.e., nitrogen source) and the EPS yield since EPS yield increases from $\sim 0.19$ to $\sim 13 \mathrm{~g} / 100 \mathrm{~mL}$ as the concentration of ammonium sulfate increases from $\sim 1.27$ to $\sim 14.73 \mathrm{~g} / 100 \mathrm{~mL}$. This observation indicates the favorable role of nitrogen on EPS production by Rhodotorula mucilaginosa sp. GUMS16. However, a critical review of existing literature shows significant variations in the effect of higher nitrogen concentrations on EPS yield. Some previous reports showed that higher nitrogen presented unfavorable effects on the EPS yield by P. acidipropionici and on the other hand, favorable effects on EPS production by $S$. thermophilus [42].

These observations suggested that the effect of nitrogen on EPS yield is microbe microbe-specific and that there is a need to determine the ideal nitrogen concentration for enhanced EPS yield on a 'case by case' basis [42].

\subsubsection{Effect of Sucrose Concentration}

Figure $2 \mathrm{c}$ highlights the marginal effect of increments in sucrose concentrations (i.e., carbon source) on the yield of EPS produced by Rhodotorula mucilaginosa sp. GUMS16. This observation is consistent with the literature, which showed positive correlations between EPS production and carbon concentration $[41,43,44]$. Some studies have highlighted that the positive effect of carbon on EPS yield is not sustained, with excessive carbon leading to a reduction in the EPS yield due to catabolite repression [45]. The absence of this effect (i.e., increasing carbon leading to decrease in EPS yield) suggests that the maximum carbon concentration may yet to be attained, with higher sucrose concentrations proposed to be studied in future investigations. Given that the results show that while higher ammonium sulfate (i.e., nitrogen source) concentrations enable higher EPS yields, higher sucrose concentrations (i.e., carbon source) lead to marginal improvements in EPS yield overall. This observation implies that lower carbon to nitrogen ratios favor enhanced EPS productivity when Rhodotorula mucilaginosa sp is employed. This observation is consistent with the study by [36] in which the EPS yield by Haloferax mediterranei was shown to present a linear and negative correlation with the $\mathrm{C} / \mathrm{N}$ ratio. In another study, variations in the $\mathrm{C} / \mathrm{N}$ ratio did not lead to changes in the EPS productivity [46], thus suggesting that the effect of the $\mathrm{C} / \mathrm{N}$ ratio on EPS yield is also microbe-specific.

Table 3 shows that variations in the ammonium sulfate $(A)$ constitutes will present the most significant independent effect on EPS yield as illustrated by the highest $F$-value of 208.80 compared to the $F$-values of 7.46 and 1.15 for $\mathrm{pH}$ value $(p)$ and sucrose concentration $(S)$ respectively. The results also imply that variations in $\mathrm{pH}$ constitute the next most significant parameter that influences EPS production, given that the associated $F$-value is greater than the critical $F$-value of 3.37. These results also indicate that the effect of variations in sucrose concentration $(S)$ present the least significant process variable given that its $F$-value of 1.15 is less than the critical $F$-value of 3.37. The calculated $F$-values of the interactions of the process variables of $p \times S, p \times A$ and $A \times S$ terms were not shown to be significant since the $F$-values were determined to be less than critical $F$-value of 3.37 .

The empirical relation in Equation (3) and the optimization algorithm in Minitab were employed in determining the conditions that facilitate optimum EPS production by Rhodotorula mucilaginosa sp. GUMS16. The conditions of $\mathrm{pH}$, sucrose concentration and ammonium sulfate concentration will facilitate the predicted optimal EPS yield of $14.83 \mathrm{~g} / 100 \mathrm{~mL}$ were $5,1 \mathrm{~g} / 100 \mathrm{~mL}$ and $14.73 \mathrm{~g} / 100 \mathrm{~mL}$, respectively. The validation of these process conditions for optimal EPS yield was undertaken, and the experimentally determined results are presented in Table 4.

Table 4 shows that the predicted optimal EPS yield at the determined conditions is comparable with the experimentally determined EPS yield, with a relative absolute error of 0.09 calculated. 
Table 3. Analysis of variance (ANOVA) of the model for the EPS production.

\begin{tabular}{ccccccc}
\hline Source & DF & Adj SS & Adj MS & $F$-Value & $p$-Value & Remarks \\
\hline Model & 9 & 226.52 & 25.17 & 24.96 & 0.00 & $* *$ \\
\hline$p$ & 1 & 7.52 & 7.52 & 7.46 & 0.02 & $* *$ \\
\hline$S$ & 1 & 1.16 & 1.16 & 1.15 & 0.31 & $*$ \\
\hline$A$ & 1 & 210.51 & 210.51 & 208.80 & 0.00 & $* *$ \\
\hline$p^{2}$ & 1 & 6.54 & 6.54 & 6.48 & 0.03 & $* *$ \\
\hline$S^{2}$ & 1 & 0.91 & 0.91 & 0.90 & 0.37 & $*$ \\
\hline$p \times S$ & 1 & 0.67 & 0.67 & 0.66 & 0.44 & $*$ \\
\hline$p \times A$ & 1 & 0.09 & 0.09 & 0.09 & 0.77 & $*$ \\
\hline$A \times S$ & 1 & 0.01 & 0.01 & 0.01 & 0.93 & $*$ \\
\hline
\end{tabular}

In Table $3, *$ denotes low significance when the $F$-value is less than 3.37 while ** denotes high significance, i.e., when the $F$-value is greater than 3.37 .

Table 4. Predicted and experimentally determined optimum EPS yields.

\begin{tabular}{ccc}
\hline $\begin{array}{c}Y_{E P S},(\mathrm{~g} / \mathbf{1 0 0} \mathbf{~ m L}) \\
\text { (Predicted. Yield) }\end{array}$ & $\begin{array}{c}\boldsymbol{Y}_{E P S},(\mathrm{~g} / \mathbf{1 0 0} \mathbf{~ m L}) \\
\text { (Exp. Yield) }\end{array}$ & Relative Absolute Error \\
\hline 14.83 & 13.48 & 0.09 \\
\hline$Y_{E P S}$ denotes the yield of exopolysaccharide.
\end{tabular}

A comparison of the optimum EPS of $13.48 \mathrm{~g} / 100 \mathrm{~mL}$ as determined in the current study with the EPS reported in previously reported works demonstrates the high productivity of the EPS from Rhodotorula mucilaginosa sp. GUMS16. Of course, the dextrose content of the PDB of $2.4 \mathrm{~g} / 100 \mathrm{~mL}$ may also contribute as a carbon source, thus may partly explain the high yield of crude EPS recorded. The yield of crude EPS from Rhodotorula mucilaginosa sp. GUMS16 may be indicative of its commercial potential since its EPS yield exceeded the reported optimal EPS yields of $2.2 \mathrm{~g} / 100 \mathrm{~mL}, 11.8 \mathrm{~g} / 100 \mathrm{~mL}$ and $12.6 \mathrm{~g} / 100 \mathrm{~mL}$ generated from Bacillus mucilaginosus CGMCC5766, Cupriavidus pauculus KPS 201 and Spirulina Platensis, respectively, reported in the literature [47-49]. The total sugar content of the optimally generated EPS was also determined using the phenol sulfuric acid method [50,51]. It was determined that the mean sugar content was $60 \%$ mass basis and was comparable to the sugar content of EPS reported in a previous work that ranges from $34-71 \%$ mass basis [52]. Other components in EPS such as proteins and macro-molecules such as DNA, lipids, and humic substances were not measured in the current study. The current study acknowledges that further purification processes involving ion-exchange chromatography and size exclusion chromatography may be required to enhance the purity of the EPS extract [53]. These additional purification steps have not been considered in the present study, implying that the EPS yield reported in the current study may be referred to as 'crude EPS'. We also acknowledge that further purification may lead to a change in the EPS yield. The impacts of such purifications on EPS yield will be investigated in future studies. Nevertheless, the present study establishes the potential of employing Rhodotorula mucilaginosa sp. GUMS16, to facilitate optimal production of useful EPS. Crucially, the current study also aligns with current research interest in the exploration of the circular economy paradigm [54], which involves the recovery of high value products (i.e., EPS) from low value feeds (i.e., 'soft' carbon sources like sucrose).

\section{Conclusions}

The present study investigated the production of extracellular polysaccharides (EPS) by Rhodotorula mucilaginosa sp. GUMS16, with emphasis on the process conditions that facilitate enhanced EPS yield. In the study, the process conditions of carbon concentra- 
tion, nitrogen concentration, and $\mathrm{pH}$ were assessed, with sucrose and ammonium sulfate employed as carbon and nitrogen precursors, respectively. The study established that changes in ammonium sulfate (nitrogen precursor) constituted the most important factor that influenced EPS yields, with sucrose (carbon precursor) concentration shown to be the least important process variable in the present study. Further investigations also established that the optimal crude EPS yield of $13.48 \mathrm{~g} / 100 \mathrm{~mL}$ from Rhodotorula mucilaginosa sp. GUMS16 was achieved at $\mathrm{pH}$, sucrose concentration and ammonium sulfate conditions of $5.1 \mathrm{~g} / 100 \mathrm{~mL} 14.73 \mathrm{~g} / 100 \mathrm{~mL}$, respectively, were imposed.

Author Contributions: Conceptualization, M.H., A.R.G. and A.S; data generation and validation, A.R.G. and F.S; methodology, O.V.O., A.S. and M.H; software, O.V.O.; validation, M.H.; writingoriginal draft preparation, A.R.G., O.V.O., M.H. and A.S.; writing—review and editing, A.R.G., F.S., O.V.O., M.H. and A.S. All authors have read and agreed to the published version of the manuscript.

Funding: This research received no external funding.

Institutional Review Board Statement: Not applicable.

Informed Consent Statement: Not applicable.

Acknowledgments: M.H. and A.R.G. acknowledge Guilan University of Medical Sciences and Guilan Science and Technology Park for providing support to this work. O.V.O. gratefully acknowledges the financial support of Wallonia-Brussels International via the Wallonie-Bruxelles International (WBI) excellence Postdoctoral fellowship.

Conflicts of Interest: The authors declare no conflict of interest.

\section{References}

1. Shanmugam, M.; Abirami, R.G. Microbial Polysaccharides-Chemistry and Applications. J. Biol. Act. Prod. Nat. 2019, 9, 73-78. [CrossRef]

2. Luft, L.; Confortin, T.C.; Todero, I.; Zabot, G.L.; Mazutti, M.A. An overview of fungal biopolymers: Bioemulsifiers and biosurfactants compounds production. Crit. Rev. Biotechnol. 2020, 40, 1059-1080. [CrossRef]

3. Castillo, N.A.; Valdez, A.L.; Farina, J.I. Microbial production of Scleroglucan and downstream processing. Front. Microbiol. 2015, 6, 1106. [CrossRef] [PubMed]

4. Sugumaran, K.; Ponnusami, V. Review on production, downstream processing and characterization of microbial pullulan. Carbohydr. Polym. 2017, 173, 573-591.

5. Hamidi, M.; Mirzaei, R.; Delattre, C.; Khanaki, K.; Pierre, G.; Gardarin, C.; Petit, E.; Karimitabar, F.; Faezi, S. Characterization of a new exopolysaccharide produced by Halorubrum sp. TBZ112 and evaluation of its anti-proliferative effect on gastric cancer cells. 3 Biotech 2019, 9, 1-8. [CrossRef] [PubMed]

6. Smelcerovic, A.; Knezevic-Jugovic, Z.; Petronijevic, Z. Microbial polysaccharides and their derivatives as current and prospective pharmaceuticals. Curr. Pharm. Des. 2008, 14, 3168-3195. [CrossRef] [PubMed]

7. Gupta, J.; Rathour, R.; Medhi, K.; Tyagi, B.; Thakur, I.S. 3-Microbial-derived natural bioproducts for a sustainable environment: A bioprospective for waste to wealth. In Refining Biomass Residues for Sustainable Energy and Bioproducts; Kumar, R.P., Gnansounou, E., Raman, J.K., Baskar, G., Eds.; Academic Press: Cambridge, MA, USA, 2020; pp. 51-85.

8. Schmid, J.; Sieber, V.; Rehm, B. Bacterial exopolysaccharides: Biosynthesis pathways and engineering strategies. Front. Microbiol. 2015, 6, 496. [CrossRef]

9. Ansorena, D.; Astiasarán, I. Fermented Foods: Composition and Health effects. In Encyclopedia of Food and Health; Caballero, B., Finglas, P.M., Toldrá, F., Eds.; Academic Press: Oxford, UK, 2016; pp. 649-655.

10. Bomfeti, C.A.; Florentino, L.A.; Guimarães, A.P.; Cardoso, P.G.; Guerreiro, M.C.; Moreira, F.M.d.S. Exopolysaccharides produced by the symbiotic nitrogen-fixing bacteria of leguminosae. Revista Brasileira Ciência Solo 2011, 35, 657-671. [CrossRef]

11. Ziadi, M.; Bouzaiene, T.; M'Hir, S.; Zaafouri, K.; Mokhtar, F.; Hamdi, M.; Boisset-Helbert, C. Evaluation of the Efficiency of Ethanol Precipitation and Ultrafiltration on the Purification and Characteristics of Exopolysaccharides Produced by Three Lactic Acid Bacteria. BioMed Res. Int. 2018, 2018, 1896240. [CrossRef]

12. Banerjee, A.; Rudra, S.G.; Mazumder, K.; Nigam, V.; Bandopadhyay, R. Structural and Functional Properties of Exopolysaccharide Excreted by a Novel Bacillus anthracis (Strain PFAB2) of Hot Spring Origin. Indian J. Microbiol. 2018, 58, 39-50. [CrossRef]

13. Freitas, F.; Torres, C.A.; Reis, M.A. Engineering aspects of microbial exopolysaccharide production. Bioresour. Technol. 2017, 245, 1674-1683. [CrossRef] [PubMed]

14. Osemwegie, O.O.; Adetunji, C.O.; Ayeni, E.A.; Adejobi, O.I.; Arise, R.O.; Nwonuma, C.O.; Oghenekaro, A.O. Exopolysaccharides from bacteria and fungi: Current status and perspectives in Africa. Heliyon 2020, 6, e04205. [CrossRef] [PubMed]

15. Mirzaei, M.; Okoro, O.V.; Nie, L.; Petri, D.F.S.; Shavandi, A. Protein-Based 3D Biofabrication of Biomaterials. Bioengineering 2021, 8, 48. [CrossRef] 
16. Shavandi, A.; Hosseini, S.; Okoro, O.V.; Nie, L.; Eghbali Babadi, F.; Melchels, F. 3D Bioprinting of Lignocellulosic Biomaterials. Adv. Healthc. Mater. 2020, 9, 2001472. [CrossRef] [PubMed]

17. Donot, F.; Fontana, A.; Baccou, J.C.; Schorr-Galindo, S. Microbial exopolysaccharides: Main examples of synthesis, excretion, genetics and extraction. Carbohydr. Polym. 2012, 87, 951-962. [CrossRef]

18. Hivechi, A.; Milan, P.B.; Modabberi, K.; Amoupour, M.; Ebrahimzadeh, K.; Gholipour, A.R.; Sedighi, F.; Amini, N.; Bahrami, S.H.; Rezapour, A.; et al. Synthesis and Characterization of Exopolysaccharide Encapsulated PCL/Gelatin Skin Substitute for Full-Thickness Wound Regeneration. Polymers 2021, 13, 854. [CrossRef]

19. Mahapatra, S.; Banerjee, D. Fungal Exopolysaccharide: Production, Composition and Applications. Microbiol. Insights 2013, 6, 1-16. [CrossRef]

20. Bhattacharyya, C.; Roy, R.; Tribedi, P.; Ghosh, A.; Ghosh, A. Chapter 11-Biofertilizers as substitute to commercial agrochemicals. In Agrochemicals Detection, Treatment and Remediation; Prasad, M.N.V., Ed.; Butterworth-Heinemann: Oxford, UK, 2020; pp. 263-290.

21. Zisu, B.; Shah, N.P. Effects of pH, Temperature, Supplementation with Whey Protein Concentrate, and Adjunct Cultures on the Production of Exopolysaccharides by Streptococcus thermophilus 1275. J. Dairy Sci. 2003, 86, 3405-3415. [CrossRef]

22. Torres, C.A.V.; Antunes, S.; Ricardo, A.R.; Grandfils, C.; Alves, V.D.; Freitas, F.; Reis, M.A.M. Study of the interactive effect of temperature and $\mathrm{pH}$ on exopolysaccharide production by Enterobacter A47 using multivariate statistical analysis. Bioresour. Technol. 2012, 119, 148-156. [CrossRef]

23. Hereher, F.; ElFallal, A.; Abou-Dobara, M.; Toson, E.; Abdelaziz, M.M. Cultural optimization of a new exopolysaccharide producer "Micrococcus roseus". Beni-Suef Univ. J. Basic Appl. Sci. 2018, 7, 632-639. [CrossRef]

24. Imran, M.Y.M.; Reehana, N.; Jayaraj, K.A.; Ahamed, A.A.P.; Dhanasekaran, D.; Thajuddin, N.; Alharbi, N.S.; Muralitharan, G. Statistical optimization of exopolysaccharide production by Lactobacillus plantarum NTMI05 and NTMI20. Int. J. Biol. Macromol. 2016, 93, 731-745. [CrossRef]

25. Ermiş, E.; Poyraz, E.; Dertli, E.; Y1lmaz, M.T. Optimization of exopolysaccharide production of Lactobacillus brevis E25 using RSM and characterization. Sakarya Üniversitesi Fen Bilimleri Enstitüsü Dergisi 2020, 24, 151-160. [CrossRef]

26. Hamidi, M.; Gholipour, A.R.; Delattre, C.; Sesdighi, F.; Seveiri, R.M.; Pasdaran, A.; Kheirandish, S.; Pierre, G.; Kozani, P.S.; Kozani, P.S. Production, characterization and biological activities of exopolysaccharides from a new cold-adapted yeast: Rhodotorula mucilaginosa sp. GUMS16. Int. J. Biol. Macromol. 2020, 151, 268-277. [CrossRef]

27. Mohammadi, R.; Mohammadifar, M.A.; Mortazavian, A.M.; Rouhi, M.; Ghasemi, J.B.; Delshadian, Z. Extraction optimization of pepsin-soluble collagen from eggshell membrane by response surface methodology (RSM). Food Chem. 2016, 190, 186-193. [CrossRef] [PubMed]

28. Okoro, O.V.; Sun, Z.; Birch, J. Experimental evaluation of a polystyrene sulphonic acid resin catalyst in the hydrolysis of low-grade lipids from the meat processing industry. Biomass Bioenergy 2018, 116, 49-59. [CrossRef]

29. Roosta, M.; Ghaedi, M.; Asfaram, A. Simultaneous ultrasonic-assisted removal of malachite green and safranin O by copper nanowires loaded on activated carbon: Central composite design optimization. RSC Adv. 2015, 5, 57021-57029. [CrossRef]

30. Nie, L.; Chang, P.; Liang, S.; Hu, K.; Hua, D.; Liu, S.; Sun, J.; Sun, M.; Wang, T.; Okoro, O.V.; et al. Polyphenol rich green tea waste hydrogel for removal of copper and chromium ions from aqueous solution. Clean. Eng. Technol. 2021, 4, 100167. [CrossRef]

31. Pavlova, K.; Koleva, L.; Kratchanova, M.; Panchev, I. Production and characterization of an exopolysaccharide by yeast. World J. Microbiol. Biotechnol. 2004, 20, 435-439. [CrossRef]

32. Pavlova, K.; Panchev, I.; Krachanova, M.; Gocheva, M. Production of an exopolysaccharide by Antarctic yeast. Folia Microbiol. 2009, 54, 343. [CrossRef] [PubMed]

33. Sutherland, I.W. Biosynthesis of Microbial Exopolysaccharides. In Advances in Microbial Physiology; Rose, A.H., Morris, J.G., Eds.; Academic Press: Cambridge, MA, USA, 1982; Volume 23, pp. 79-150.

34. Wang, Y.-C.; Lin, F.-Y.; Hsu, T.-H. Effects of Nitrogen from Different Sources on Mycelial Biomass and Polysaccharide Production and Pellet Morphology in Submerged Cultures of Grifola frondosa. BioResources 2021, 16, 2937-2952. [CrossRef]

35. Valentino, F.; Karabegovic, L.; Majone, M.; Morgan-Sagastume, F.; Werker, A. Polyhydroxyalkanoate (PHA) storage within a mixed-culture biomass with simultaneous growth as a function of accumulation substrate nitrogen and phosphorus levels. Water Res. 2015, 77, 49-63. [CrossRef]

36. Cui, Y.-W.; Shi, Y.-P.; Gong, X.-Y. Effects of C/N in the substrate on the simultaneous production of polyhydroxyalkanoates and extracellular polymeric substances by Haloferax mediterranei via kinetic model analysis. RSC Adv. 2017, 7, 18953-18961. [CrossRef]

37. Braun, M.; Altan, H.; Beck, S.J.A.E. Using regression analysis to predict the future energy consumption of a supermarket in the UK. Appl. Energy 2014, 130, 305-313. [CrossRef]

38. Okoro, O.V.; Sun, Z.; Birch, J.J.S. Catalyst-free biodiesel production methods: A comparative technical and environmental evaluation. Sustainability 2018, 10, 127. [CrossRef]

39. Goh, K.K.T. Isolation and Characterisation of Bacterial Exopolysaccharide Produced by Lactobacillus Delbrueckii Subsp Bulgaricus NCFB 2483 and Sphingomonas Elodea ATCC31461. Ph.D. Thesis, Massey University, Palmerston North, New Zealand, 30 July 2004.

40. Seesuriyachan, P.; Kuntiya, A.; Techapun, C. Exopolysaccharide production by Lactobacillus confusus TISTR 1498 using coconut water as an alternative carbon source: The effect of peptone, yeast extract and beef extract. Sonklanakarin J. Sci. Technol. 2011, 33,379 . 
41. Cho, D.H.; Chae, H.J.; Kim, E.Y. Synthesis and characterization of a novel extracellular polysaccharide by Rhodotorula glutinis. Appl. Biochem. Biotechnol. 2001, 95, 183-193. [CrossRef]

42. Lo, Y.M.; Argin-Soysal, S.; Hsu, C.-H. Chapter 22-Bioconversion of Whey Lactose into Microbial Exopolysaccharides. In Bioprocessing for Value-Added Products from Renewable Resources; Yang, S.-T., Ed.; Elsevier: Amsterdam, The Netherlands, 2007; pp. 559-583.

43. Kaditzky, S.; Vogel, R.F. Optimization of exopolysaccharide yields in sourdoughs fermented by Lactobacilli. Eur. Food Res. Technol. 2008, 228, 291. [CrossRef]

44. Ryan, P.; Ross, R.; Fitzgerald, G.; Caplice, N.; Stanton, C. Sugar-coated: Exopolysaccharide producing lactic acid bacteria for food and human health applications. Food Funct. 2015, 6, 679-693. [CrossRef]

45. Maalej, H.; Hmidet, N.; Boisset, C.; Buon, L.; Heyraud, A.; Nasri, M. Optimization of exopolysaccharide production from Pseudomonas stutzeri AS22 and examination of its metal-binding abilities. J. Appl. Microbiol. 2015, 118, 356-367. [CrossRef] [PubMed]

46. Van Dyk, J.S.; Kee, N.L.A.; Frost, C.L.; Pletschke, B.I. Extracellular polysaccharide production in Bacillus licheniformis SVD1 and its immunomodulatory effect. BioResources 2012, 7, 4976-4993. [CrossRef]

47. Pal, A.; Paul, A.K. Optimization of Cultural Conditions for Production of Extracellular Polymeric Substances (EPS) by Serpentine Rhizobacterium Cupriavidus pauculus KPS 201. J. Polym. 2013, 2013, 692374. [CrossRef]

48. Li, H.; Li, J.; Dou, W.; Shi, J.; Xu, Z. Enhancing the production of a novel exopolysaccharide by Bacillus mucilaginosus CGMCC5766 Using Statistical experiment design. Trop. J. Pharm. Res. 2013, 12, 711-718. [CrossRef]

49. Nagananthini, G.; Rajapriya, S.; Arivuvel, P.S. Extraction And Optimization Of Extracellular Polysaccharide Production In Spirulina Platensis MK 343101. Int. J. Sci. Technol. Res. 2020, 9, 1-5.

50. Vinothini, G.; Latha, S.; Arulmozhi, M.; Dhanasekaran, D. Statistical optimization, physio-chemical and bio-functional attributes of a novel exopolysaccharide from probiotic Streptomyces griseorubens GD5. Int. J. Biol. Macromol. 2019, 134, 575-587. [CrossRef]

51. Wang, B.; Song, Q.; Zhao, F.; Han, Y.; Zhou, Z. Production optimization, partial characterization and properties of an exopolysaccharide from Lactobacillus sakei L3. Int. J. Biol. Macromol. 2019, 141, 21-28. [CrossRef] [PubMed]

52. Gomaa, M.; Yousef, N. Optimization of production and intrinsic viscosity of an exopolysaccharide from a high yielding Virgibacillus salarius BM02: Study of its potential antioxidant, emulsifying properties and application in the mixotrophic cultivation of Spirulina platensis. Int. J. Biol. Macromol. 2020, 149, 552-561. [CrossRef]

53. Leroy, F.; De Vuyst, L. Advances in production and simplified methods for recovery and quantification of exopolysaccharides for applications in food and health1. J. Dairy Sci. 2016, 99, 3229-3238. [CrossRef] [PubMed]

54. Okoro, O.V.; Sun, Z. The characterisation of biochar and biocrude products of the hydrothermal liquefaction of raw digestate biomass. Biomass Convers. Biorefin. 2020. [CrossRef] 